Original Research Paper

\title{
Pengenalan Diversifikasi Pengolahan Air Nira Menjadi Gula Aren dan Gula Semut Serta Berbagai Aneka Rasa Minuman di Desa Langko Kecamatan Lingsar Lombok Barat
}

\author{
Ahmad Jupri $^{1 *}$, Hilman Ahydi ${ }^{2}$, Tapaul Rozi ${ }^{3}$, Nurhasanah ${ }^{4}$ \\ 1,2 Program Studi Pendidikan Lingkungan FPMIPA Universitas Mataram, Jl. Majapahit 62 Mataram - NTB 83125 \\ 3 Program Studi Imu Produksi Ternak FPt Universitas Mataram, Jl. Majapahit 62 Mataram - NTB 83125 \\ 4 Program Studi PGSD FKIP Universitas Mataram, Jl. Majapahit 62 Mataram - NTB 83125
}

DOI: https://doi.org/10.29303/jpmpi.v3i2.526

Sitasi : Jupri, A., Ahydi. H., Rozi, T., \& Nurhasanah. (2020). Pengenalan Diversifikasi Pengolahan Air Nira Menjadi Gula Aren dan Gula Semut Serta Berbagai Aneka Rasa Minuman di Desa Langko Kecamatan Lingsar Lombok Barat. Jurnal Pengabdian Magister Pendidikan IPA, 3(2)

\section{Article history}

Received: 30 September 2020

Revised: 14 Oktober 2020

Accepted: 19 Desember 2020

*Corresponding Author:

Ahmad Jupri,

Program Studi

Pendidikan Lingkungan,

FPMIPA,

Universitas Mataram,

Indonesia.

Email:

juprizikril@gmail.com

\begin{abstract}
Abstrak: Desa Langko termasuk kecamatan Lingsar Lombok Barat. Posisinya cukup strategis karena jaraknya hanya 15 kilo meter dari Mataram Desa Langko yang memiliki perbatasan dengan hutan tertutup terutama dusun Longserang Barat Utara dan Dusun Longserang Barat Selatan yang banyak ditumbuhi oleh POHON AREN menjadikan desa ini sebagai penghasil dan pemasok utama air nira ke kota Mataram, di kota Mataram air nira ini dijadikan sebagai bahan baku untuk membuat minuman keras seperti tuak toak atau brem yang bisa memabukkan. Hal ini yang perlu mendapat sorotan dan perhatian dari kami dari Universitas Mataram untuk segera memberi solusi yaitu solusi di bidang sosial dan ekonomi kemasyarakatan. Solusi dibidang ekonomi antara lain warga masyarakat di desa Langko mendapat hasil yang lebih baik dari pengolahan air nira menjadi gula aren dan gula semut dan berbagai aneka rasa minuman yang harganya lebih mahal. Langkah yang diambil adalah memberikan mereka pengetahuan dan mengajarkan serta melatih mereka untuk mengolah air nira tersebut selain menjadi gula aren tetapi juga bisa diolah menjadi gula semut (karena harga gula semut lebih mahal dari gula aren) dan berbagai aneka rasa minuman. Pembuatan gula semut dapat dilakukan melalui dua cara yaitu, pertama gula semut dapat dibuat langsung dari air nira yang baru diturunkan dari pohon aren dan langsung diolah; cara kedua adalah gula semut dapat dibuat dengan pengolahan lanjutan gula aren yang sudah jadi dan hanya membutuhkan waktu sekita 30 menit.
\end{abstract}

Kata Kunci: Nira, Gula Aren, Gula Semut, Minuman Aneka Rasa

\section{Pendahuluan}

$\mathrm{D}$ esa Langko adalah salah satu desa di kecamatan Lingsar Lombok Barat Nusa
Tenggara Barat. Posisi desa ini cukup strategis karena tidak terlalu jauh dari pusat kota Mataram yaitu sekitar 15 kilometer. Disamping sebagai penghasil padi/beras dan buah seperti kelapa, mangga, duren, nenas, pisang, singkong dan lain- 
lain, desa Langko juga terkenal sebagai sayur antara lain kacang panjang, terong, pare, kangkung, sawi, bayam dan lain-lain yang dijual ke pasar Induk Mandalika maupun pasar tradisional desa Langko juga desa tetangganya yaitu pasar desa Duman.

Disamping potensi tersebut diatas ternyata posisi desa Langko yang memiliki perbatasan dengan hutan tertutup terutama dusun Longserang Barat Utaradan Dusun Longserang Barat Selatan yang banyak ditumbuhi oleh POHON AREN menjadikan desa ini sebagai penghasil dan pemasok utama air nira ke kota Mataram, di kota Mataram air nira ini dijadikan sebagai bahan baku untuk membuat minuman keras seperti tuak toak atau brem yang bisa memabukkan. Hal ini yang perlu mendapat sorotan dan perhatian dari kami dari Universitas Mataram untuk segera memberi solusi yaitu solusi dibidang sosial dan ekonomi kemasyarakatan. Masyarakat di desa Langko mendapat hasil yang lebih baik dari pengolahan air nira menjadi gula aren dan gula semut dan berbagai aneka rasa minuman, selanjutnya dengan diperoleh hasil yang lebih baik secara ekonomi maka pasokan air nira ke kota Mataram berkurang, diharapkan masalah sosial akibat berkurangnya pasokan air nira ke kota Mataram bisa ditekan.

Dari pantauan kami di lapangan jumlah air nira dari desa Langko yang dikirim setiap hari ke kota Mataram berkisar antara ratusan liter bahkan ribuan liter, modusnya antara lain menggunakan kemasan yang sangat teratur untuk mengelabui aparat yanitu menggunakan sepeda motor bahkan dengan kendaraan roda empat atau mobil

Luas wilayah desa langko yaitu 361,72 Ha yang terdiri atas tanah sawah (30\%), kebun (25\%), tegalan (30\%) dan pekarangan sebanyak $15 \%$. Sistem irigasi pertaniannya yaitu ada yang sistem irigasi teknis dan sistem irigasi tadah hujan, karena posisi desa Langko termasuk di kaki anak gunung Rinjani; jadi banyak wilayahnya yang berbukit-bukit dan ditanami pohon-pohon penghasil buah antara lain kelapa, mangga, duren, nenas, pisang dan lain-lain.
Desa Langko dengan jumlah total penduduk 6.278 jiwa dengan jumlah KK 2.294; hampir sepertiganya jumlah tersebut berprofesi sebagai petani dan buruh tani dan hampir setengahnya belum bekerja. Selain sebagai petani dan buruh tani, sebagian penduduk juga bekerja sebagai peternak memelihara sapi, kerbau, kambing, ayam dan bebek. Desa Langko terbagi menjadi tujuh (7) dusun/lingkungan yaitu dusun Sangiang, Langko Lauk, Langko Daye, Muhajirin, Longserang Timur, Longserang Barat Utara dan Longserang Barat Selatan (LBS). Di dusun Longserang Barat Selatan terdapat Kelompok tani“LBS Mandiri," kelompok tani geger girang merupakan kelompok tani yang berada di desa Langko kecamatan Lingsar kabupaten Lombok Barat terbentuk atas dasar musyawarah bersama guna menunjang kesamaan pendapat dalam mewujudkan peningkatan kesejahteraan petani.

Tujuan dari penelitian ini adalah untuk Untuk memberikan kesadaran dan pemahaman warga masyarakat desa Langko bahwa mereka memiliki potensi berupa sumber daya alam berupa pohon aren atau pohon nao juga pohon kelapa yang menghasilkan air nira yang jumlahnya melimpah. Memberikan pengetahuan kepada warga masyarakat desa langko bahwa air nira tersebut juga bisa diolah selain jadi gula aren juga bisa diolah menjadi gula semut dan berbagai aneka rasa minuman yang harganya lebih mahal dan dapat memberikan penghasilan yang lebih baik daripada hanya mengolahnya menjadi gula aren saja. Memberikan pelatihan untuk meningkatkan keterampilan masyarakat desa Langko cara membuat gula semut dan membentuk kelompok pengrajin gula semut agar lebih mudah mengkoordinir dalam memberikan pelatihan dan keterampilan.

\section{Metode}

Kegiatan ini menggunakan teknik Focus Group Discussion (FGD) yang melibatkan kelompok-kelompok masyarakat, kelompok pemuda dan ibu rumah tangga yang ada di Desa Langko dimana sosialisasi tentang bagaimana 
pengolahan air nira menjadi gula semut dan berbagai minuman aneka rasa .

Pelatihan dan bimbingan teknis pembuatan gula semut. Bantuan teknologi berupa : Metode dan bimbingan teknis pengolahan air nira menjadi gula semut, bahan dan peralatan yang dibutuhkan untuk kegiatan ini

\section{Hasil dan Pembahasan}

Bahan dasar pembuatan gula semut adalah air nira (air nira terdiri atas nira aren, nira kelapa dan nira tebu). Pembuatan gula semut dapat dilakukan melalui dua cara yaitu, pertama gula semut dapat dibuat langsung dari air nira yang baru diturunkan dari pohon aren dan langsung diolah menjadi gula semut; cara kedua adalah gula semut dapat dibuat dengan pengolahan lanjutan gula aren yang sudah jadi dan hanya membutuhkan waktu sekita 30 menit. Masyarakat desa Langko pada umumnya sudah terampil membuat gula aren karena merupakan kegiatan sehari-hari yang mereka lakukan, oleh karena itu dalam kegiatan ini, kami melanjutkan kegiatan membuat gula semut menggunakan bahan dasar gula aren yang sudah jadi untuk dilanjutkan prosesnya sekita 30 menit dilakukan pengolahan sehingga terbentuk produk jadi berupa gula semut yng sudah siap dikonsumsi atau dikemas. Berikut beberapa gambar rangkainan kegiatan yang dilaksanakan bersama masyarakat desa Langko :

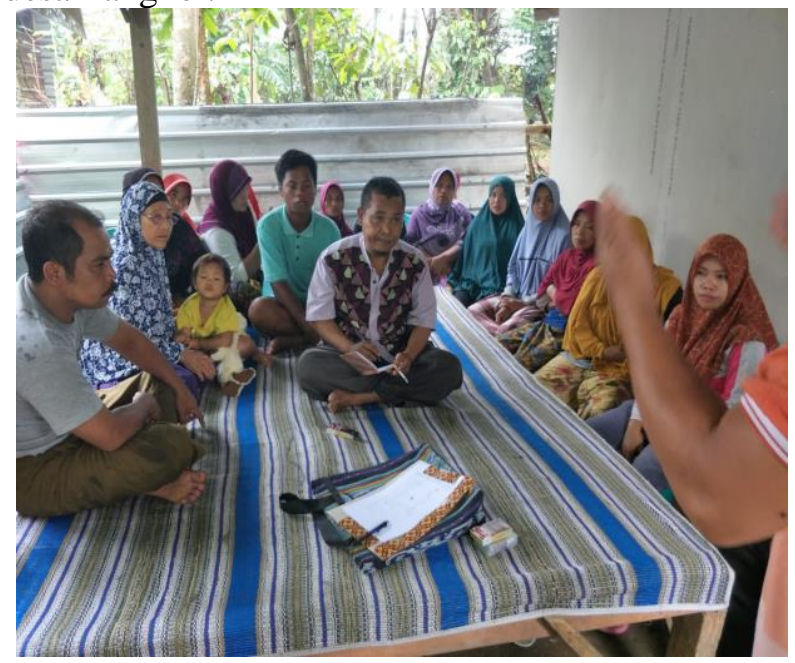

Gambar 1. Para peserta yang terdiri dari para pemuda, pemudi, ibu-ibu dan bapakbapak sedang khusuk mendengarkan penjelasan dari nara sumber tentang prospek dan keuntungan membuat gula semut.

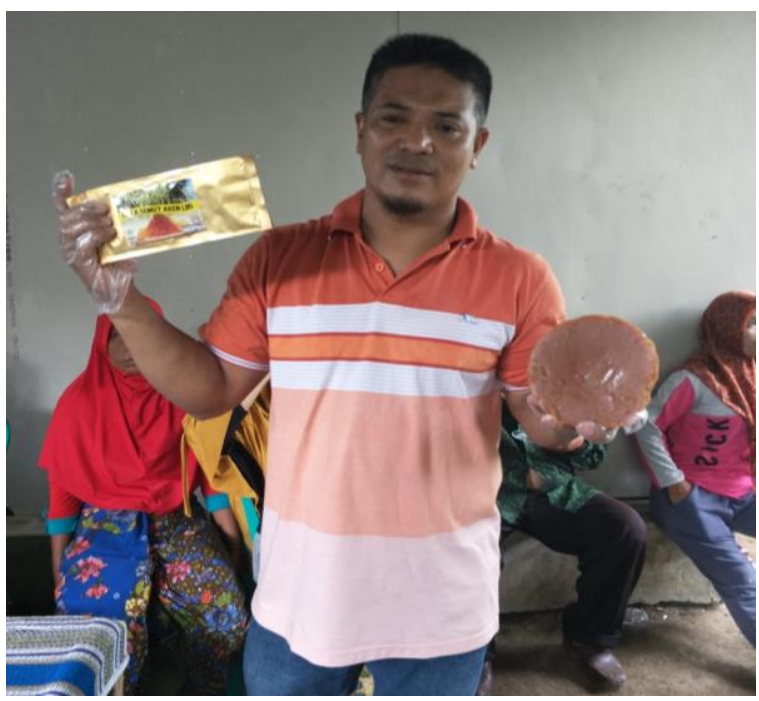

Gambar 2. Nara sumber memperlihatkan bahan dasar gula semut dari sgula aren yang siap diproses dan hasilnya gula semut yang sudah jadi dan sudah dalam kemasan

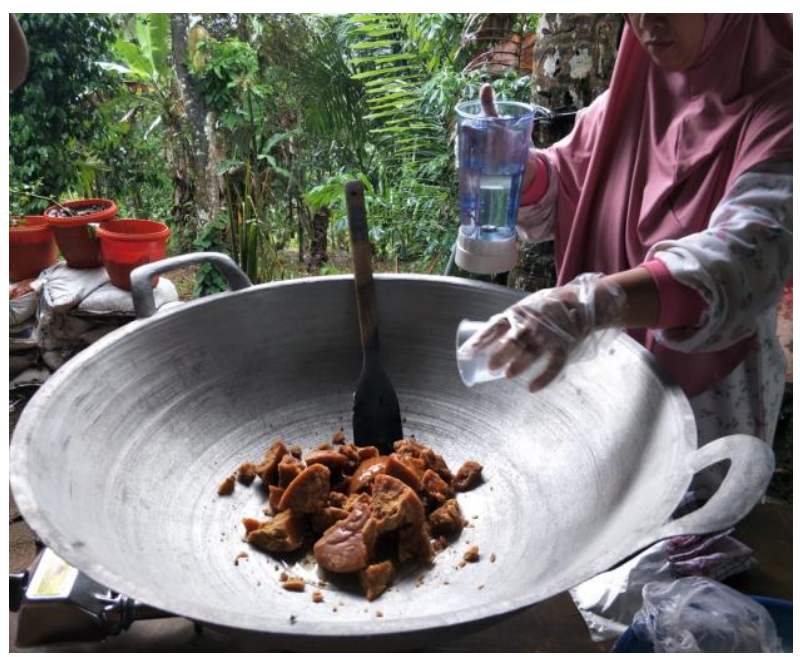

Gambar 3. Praktek dimulai dengan memecah gula aren yang sudah disiapkan menjadi bagian yang lebih kecil dan ditamahkan air secukupnya di dalam wajan lalu kompor mulai dinyalakan dengan api yang cukup kecil. 
Jupri et al, Jurnal Pengabdian Magister Pendidikan IPA, 2020, 3 (2): 205-209

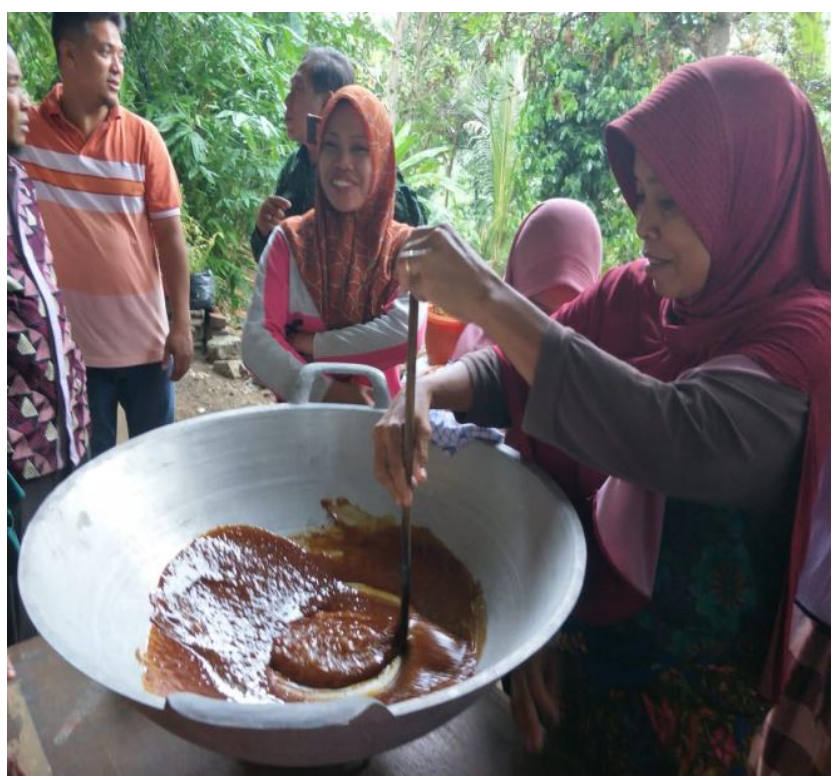

Gambar 4. Setelah mendidih mulai dilakukan pengadukan secara perlahan lahan dengan cara memutar sampai adonan/airnya mengering.

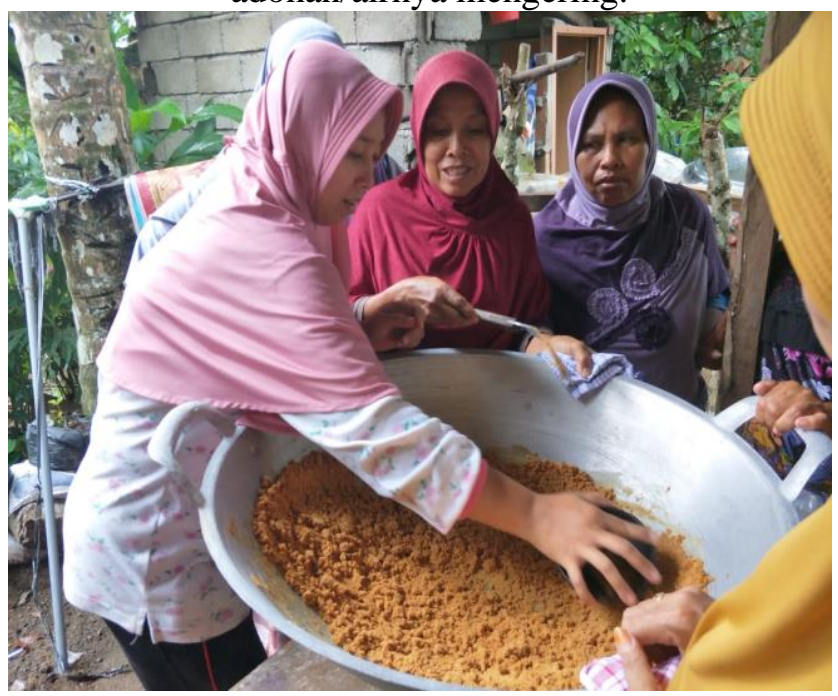

Gambar 5. Adonan gula yang sudah mengering dan mulai dihaluskan dengan cara diguser secara perlahan menggunakan batok kelapa yang sudah disiapkan dengan arah gerakan memutar atau arah kiri kanan.

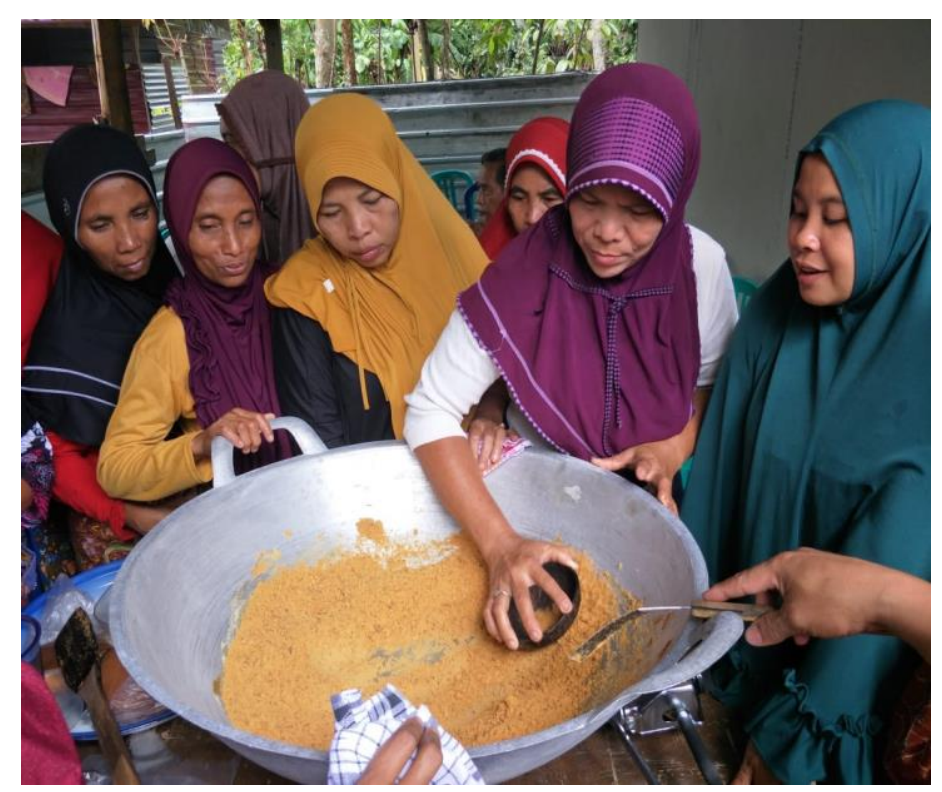

Gambar 6. Para peserta dengan antusias untuk mencoba secara bergiliran untuk menghaluskan gula yang sudah kering.

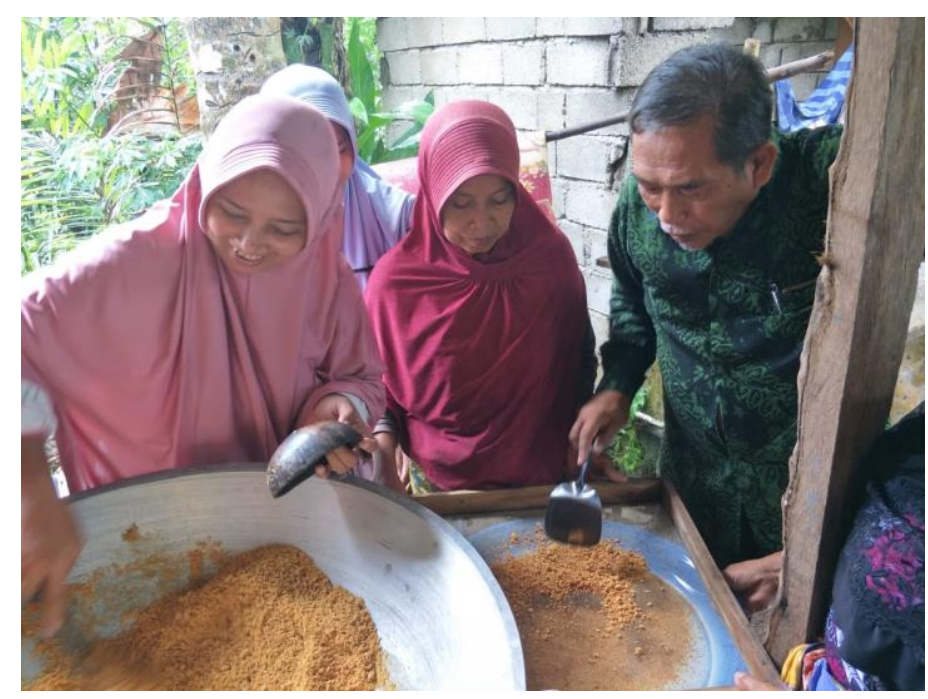

Gambar 7. Proses selanjutnya setelah gula sudah halus maka dilakukan pengayakan berulang agar butiran gula yang dihasilkan cukup halus sesuai dengan ukuran yang diinginkan. Gula yang sudah dihasilkan perlu dilakukan pengopenan atau penjemuran dengan sinar mathari sekita 6 jam agar kadar air gula semut yang diuhasilkan rendah. 


\section{Kesimpulan}

Bahan dasar pembuatan gula semut adalah air nira (air nira terdiri atas nira aren, nira kelapa dan nira tebu). Pembuatan gula semut dapat dilakukan melalui dua cara yaitu, pertama gula semut dapat dibuat langsung dari air nira yang baru diturunkan dari pohon aren dan langsung diolah menjadi gula semut; cara kedua adalah gula semut dapat dibuat dengan pengolahan lanjutan gula aren yang sudah jadi dan hanya membutuhkan waktu sekita 30 menit.

\section{Daftar Pustaka}

Anonim, 2017, Propfil Desa Langko Kecamatan Lingsar Lombok Barat

AOAC. 2006. Official Methods Of Analysis of The Association Of Official Analytical Chemistry. AOAC. Int., Washington D. C

Apriyantono, A., D. Fardiaz, N. L. Puspitasari, Sedamawati dan S. Budiyanto., 1989. Analisis Pangan. PAU Pangan dan Gizi. IPB Press. Bogor

Dyanti, 2002. Studi Kompratif Gula Merah Kelapa dan Gula Merah Aren. Skripsi. IPB. Bogor

Febrianto, Arie,M,. 2011. Studi Kelayakan Pendirian Unit Pengolahan Gula Semut Dengan Pengolahan Sistem Reprosesing Pada Skala Industri Menengah Di Kabupaten Blitar. Proceeding Lokakarya Nasional Pemberdayaan Potensi Keluarga Tani Untuk Pengentasan Kemiskinan

Rahayu, W.P. 2001. Penuntun Praktikum Penilaian Organoleptik. Jurusan Teknologi Pangan dan Gizi. Fakultas Teknologi Pangan. IPB. Bogor

Siregar, C.J.P. dan Wikarsa, S. 2010. Teknologi Farmasi Sediaan Tablet: Dasar-Dasar Praktis. EGC. Jakarta.

Sudarmadji,S., Haryono dan Suhardi. 1997. Prosedur Analisis untuk Bahan Makanan dan Pertanian. Edisi Ketiga. Penerbit Liberty. Yogyakarta

Suroso dan Suyitno. 2014. Pembuatan Gula Semut Dari Bahan Baku Gula Kelapa Cetak Dengan Suhu Akhir Pemasakan terhadap Kualitas Produk yang Dihasilkan. Skripsi. Jurusan THP. Fakultas
Teknologi Pertanian. INSTIPER Yogyakarta

Yuwono,S dan Susanto, T. 2001. Pengujian Fisik Pangan. Fakultas T eknologi Pertanian. Universitas Brawijaya. Malang 